Rakenteiden Mekaniikka (Journal of Structural Mechanics)

Vol. 50, No 3, 2017, pp. $313-317$

https://rakenteidenmekaniikka.journal.fi/index

https://doi.org/10.23998/rm.65060

(c) The author(s) 2017.

Open access under CC BY-SA 4.0 license.

\title{
Contact sealing simulation of high pressured diesel injector
}

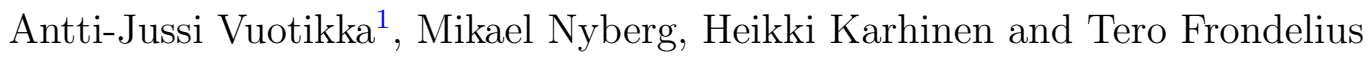

Summary. This extended abstract illustrates the simulation challenges related to highly pressurized diesel injector components and assemblies or other corresponding structures.

Key words: sealing performance, metal-to-metal sealing surface, slip, FEM, fuel injection

Received 22 June 2017. Accepted 15 August 2017. Published online 21 August 2017

\section{Introduction}

There are numerous applications where sealing properties are needed between components which deliver different liquid or gas substances. In the literature, many of the articles [1, $2,9]$ handle ordinary bolted flange joints which use gaskets for sealing. Injector assemblies use mostly non-gasketed metal-to-metal sealing tightened by pre-tensioned bolts or cap nuts. Metal-to-metal contacts are studied in several articles: [3, 9]. The following figure 1 shows a commonly used contact surface type between components.
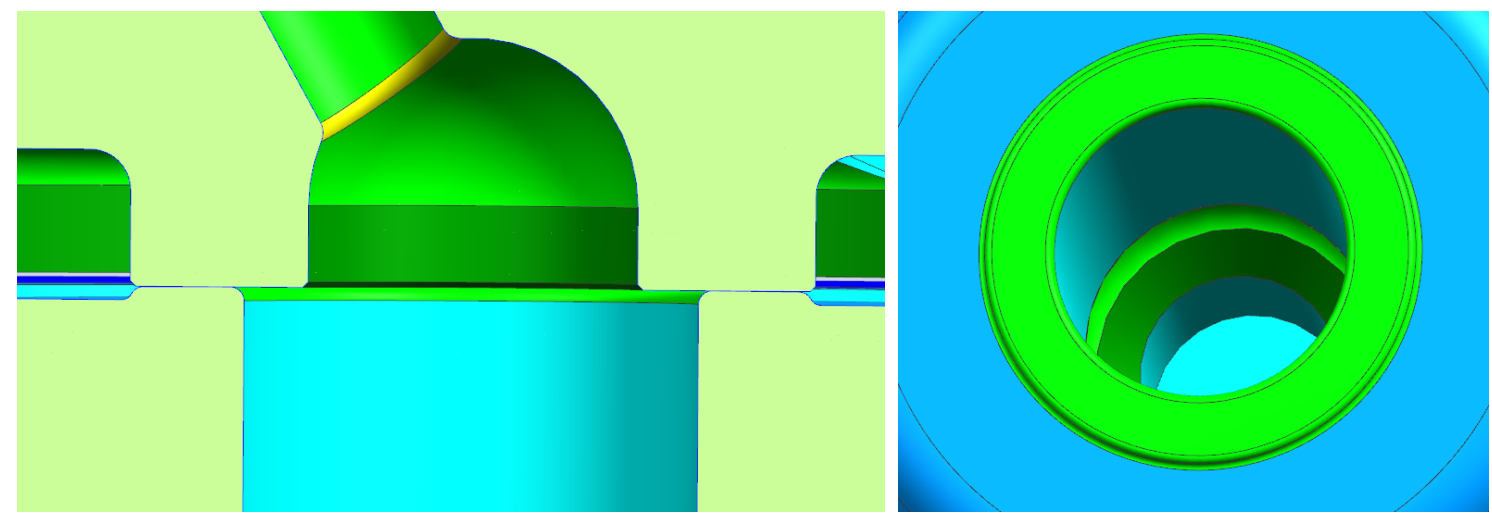

Figure 1. A highly pressurized diesel channel's contact sealing surface is shown in a cut view figure at left and the lower part above the sealing surface at right. The injector boundary conditions are coming from the cylinder head simulation model [8]. It restricts the possibilities which can be used in these structures.

\footnotetext{
${ }^{1}$ Corresponding author. antti.vuotikka@gbw.fi
} 
The contact pressure between sealing surfaces must be higher than the diesel oil pressure in the sealed channel. Otherwise the contact surface leaks. The contact pressure can be adjusted by changing the pre-tension force or changing the contact surface area. The tightening changes in pre-tensioned joints are studied in article [5] and the leaking condition in [1].

Too high a pre-tension force induces plastic deformations near sealing surfaces when the yield limit is exceeded. If surface treatments are used, the yield limit of the material can be enhanced near the surfaces and thus a higher pre-tension force is possible to be used. On the other hand, the ultimate strain limit is then lower and the material is brittle.

Depending on stiffness differences between components and the used pre-tension force, it is possible that slip behavior occurs between the sealing surfaces during the diesel pressure cycles. The contact surfaces are usually grinded to get a smooth surface and thus better sealing ability. On the other hand, contact surfaces are susceptible to slip due to a lower coefficient of friction.

Sealing difficulties may occur due to different reasons: Pressurized channels do not reach the contact surface near the proper angles or several channels are close to each other. The contact surfaces are complex and large or not equally distributed between components. Usually, the contact pressure might be too low in some parts of the contact surface. [4] lists several reasons especially for micro leaks: non-accurate surface flatness, increased surface roughness, and its orientation.

High pre-tension forces induce high static stress states near the contact surfaces. Due to pressure fluctuation inside pressure channels, the contact surfaces also experience a changing stress state. Small amplitudes can be severe for the high cycle fatigue endurance of the material. Injector fatigue calculations are done similarly as in [10, 7].

Low-cycle fatigue issues can appear if the assembly is dismantled and the component pre-tension is released several times, for example, due to the maintenance cycle. Another source for the low-cycle fatigue is the changing temperature distribution in the assembly which might occur much more often than the maintenance breaks.

\section{Challenges with injector simulation}

The several points mentioned in the introduction chapter give a hint of the difficulties faced in simulation process. The work can be started by using simple formulas and rules of thumb, but the designer is really soon in the situation where s/he needs the aid of FEM to reach a workable structure. Usually, the final version of these complex structures must also be tested in a laboratory, but this can not be the only method to develop structures due to long iteration cycle.

It is normal that fast iteration cycles are demanded nowadays, and the simulation model must give a quick response to the designers when they change the geometry of the components. Analyzing a large assembly is easily very time consuming and several needs are fighting against simplification: The complex loading and boundary conditions of the structure lead to the need of modeling the complete assembly all at once. This brings up the need of controlling the amount of DOF so that the analysis time is not prolonged too much. The simulation model should be built so that the modified components can be changed easily.

Tetra elements are used due to an easier and much faster meshing process compared to hexa elements, although hexa elements would behave better in a contact analysis. The element mesh size varies widely through the meshed components because the contact 
surfaces need a really dense mesh to give a realistic estimate of the sealing capability of the joint. A dense mesh is needed because the material parameters can vary greatly due to the thin surface treatment layer and the surfaces can have micro shapes to enhance their sealing ability. On the other hand, it is necessary to use a large element size in all other not so important locations to prevent too high amounts of DOF and a long analysis time.

Difficulties to find efficient convergence on analysis of ab assembly with several components originate from the following points: Several contact surfaces are defined in different directions. Some of the components don't have a well-defined starting condition if the components have no boundary constraints but only a surface contact to the other components. Tie constraints would help in this issue, but usually all sealing surfaces have to be studied and thus this means a growing amount of models to be analyzed. Assemblies may contain impact bushes or other parts which are shrink-fitted to other parts. It is not always possible to avoid a situation where the thread region is near sealing surfaces, and then it is important to add a thread contact to the simulation. The micro shapes usually hinder the use of adjustment and clearances options because they can influence the surface shapes. The only exception is the situation where the contact surfaces have a clear axisymmetric shape and surface smoothing can be used.

There are also challenges in finding realistic material parameters and the way of using them properly in the different parts of the analysis chain: Several exotic materials are used, and not even all of their basic physical material properties are always well known, not to mention other properties like the fatigue parameters. Different surface treatment methods produce surface layers in the components, raising their surface hardness. The friction coefficient and elastic slip for the contact surfaces should be defined by using realistic test conditions.

The complex and large models lead to a situation where the analyst encounters difficulties with result handling. Several iteration cycles of the model produce an amount of data that easily reaches the level of tera bytes. It is expected that Wärtsilä's new Digital Design Platform [6] will make simulation data management much more flexible and efficient.

\section{Contact slipping and consequences}

Despite the tremendous surface pressures in fuel injector components, the contacts will usually slip during the operation. The slip is mainly caused by pressure loads and component geometry near the contact areas, but another significant factor in some cases comes from thermal loads and support boundaries. The slip can not be avoided, but it can be controlled by using suitable contact surface geometries. Also, the intended lifetime and service intervals of the injector play a key role since the number of slip cycles plays a key role.

The slip can be divided into several main categories which all should be evaluated: initial slip, low cycle slip, operation mode switch slip and high cycle slip.

Initial slip occurs at the first on-off type pressure load sequence of the component right after its assembly when the pressure load sets components to static positions with deformed geometry. The slip can be very high but usually not in dangerous proportions. The results of the initial slip can be partially ignored since it occurs only once. The focus should be on the clearances and deformed shapes after the initial slip to ensure that they remain within such limits that the injector will work normally. The deformed state after 
the first on-off pressure pulse will be used as the reference state for low-cycle slip analysis.

Low-cycle slip occurs through low-cycle load steps of a fuel injector, such as the initial pressurization of a common rail system, thermal loading, engine load variation, disturbance or similar - in principle, all load steps between the start and stop of the engine. The slip amplitude through low-load cycles is calculated from the reference state and evaluated by calculating the relative slip between each load step and the slip amplitude over load history. The slip amplitude can be high; even 100 micrometer slip through low-cycle load steps is possible. Thus, the slip occurs between engine starts and stops, and therefore the number of slip cycles can be low. Generally, it is considered that an injector body would face less than 20000 low-cycle loads between the service intervals, but it might be possible, depending on the engine operation purpose, that an injector can go through less than ten. The relative slip between individual load steps is evaluated and the number of occurrence as well.

In modern, large fuel injectors, there are applications with a secondary pressure circuit with engine load mode options. The contacts may face slipping during the mode switch and settling to a new, statically stable position. The slip is usually large between the settled contact positions and occurs at every mode switch during the injector lifetime. Depending on the engine operational conditions, the slip and operation mode switches should be evaluated as a cumulative slip.

High-cycle slip occurs between each engine cycle and is usually low. However, the occurrence is huge, millions of cycles. Therefore, this slip is the primary one and should be minimized.

The slip causes abrasive corrosion on the contact surfaces, eventually leading to different failures. Primary failures are decreasing contact pressure, which leads to contact leakage or cavitation through the contact, and corrosion debree, which leads to malfunctions in mechanisms. These failures are safe. The secondary failures are fretting on the contact edges and cracks, see Figure 2, which may propagate easily due to high pressure load penetrating to crack. Secondary failures are rare, but can lead to severe destruction.
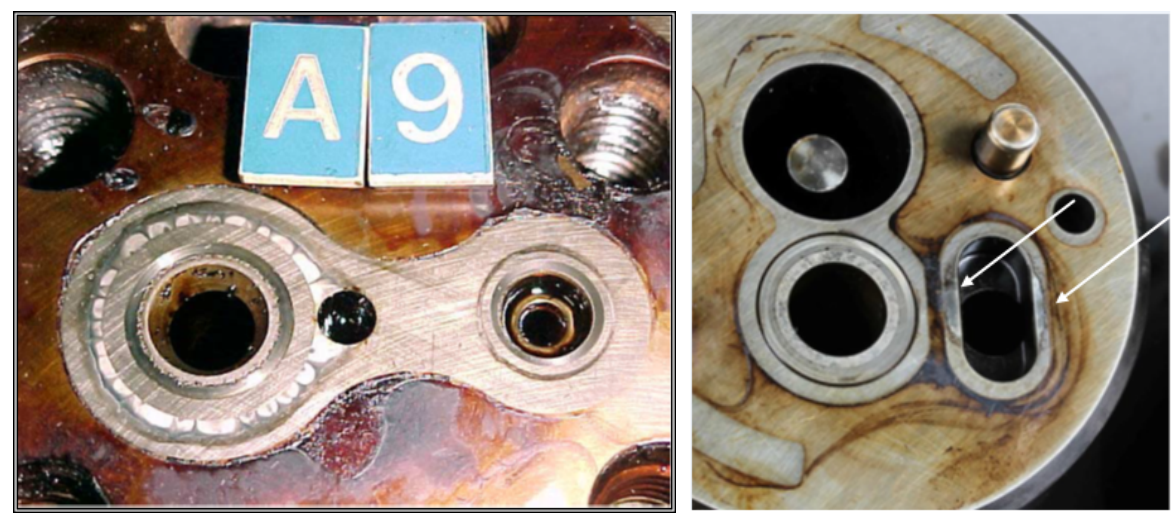

Figure 2. On the left: example of contact area fretting due to high cycle slip. On the right: contact area slip resulted to low contact pressure. Arrows point where leakage occurred on through the contact.

\section{References}

[1] M. Abid. Determination of gasketed and non-gasketed flanged pipe joint's capacity subjected to combined loading: An experimental approach. International Journal of Me- 
chanics and Materials in Design, 2(1):35-47, 2005. ISSN 1573-8841. URL https: //doi.org/10.1007/s10999-005-0519-6.

[2] M Abid and D.H Nash. Comparative study of the behaviour of conventional gasketed and compact non-gasketed flanged pipe joints under bolt up and operating conditions. International Journal of Pressure Vessels and Piping, 80(12):831 - 841, 2003. ISSN 03080161. URL https://doi.org/10.1016/j.ijpvp.2003.11.013.

[3] M Abid and D.H Nash. A parametric study of metal-to-metal contact flanges with optimised geometry for safe stress and no-leak conditions. International Journal of Pressure Vessels and Piping, 81(1):67 - 74, 2004. ISSN 0308-0161. URL https://doi.org/10.1016/j. ijpvp. 2003.11.012.

[4] M. Beghini, L. Bertini, C. Santus, A. Guglielmo, and G. Mariotti. Partially open crack model for leakage pressure analysis of bolted metal-to-metal flange. Engineering Fracture Mechanics, 144:16 - 31, 2015. ISSN 0013-7944. URL https://doi.org/10.1016/j. engfracmech.2015.06.005.

[5] Satoshi Izumi, Takashi Yokoyama, Atsushi Iwasaki, and Shinsuke Sakai. Three-dimensional finite element analysis of tightening and loosening mechanism of threaded fastener. Engineering Failure Analysis, 12(4):604 - 615, 2005. ISSN 1350-6307. URL https://doi.org/ 10.1016/j.engfailanal.2004.09.009.

[6] Juho Könnö, Hannu Tienhaara, and Tero Frondelius. Wärtsilä digital design platform. Rakenteiden Mekaniikka, 50(3):234-238, 2017. URL https://doi.org/10.23998/rm.64621.

[7] Asko Kumpula, Joona Vaara, Anton Leppänen, and Tero Frondelius. Nodular cast iron ONERA fatigue model fitting. Rakenteiden Mekaniikka, 50(3):179-181, 2017. URL https: //doi.org/10.23998/rm.64740.

[8] Anton Leppänen, Asko Kumpula, Joona Vaara, Massimo Cattarinussi, Juho Könnö, and Tero Frondelius. Thermomechanical fatigue analysis of cylinder head. Rakenteiden Mekaniikka, 50(3):182-185, 2017. URL https://doi.org/10.23998/rm.64743.

[9] Nao-Aki Noda, Akifumi Inoue, Masato Nagawa, and Fumitaka Shiraishi. The effect of material difference and flange nominal size on the sealing performance of new gasketless flanges. International Journal of Pressure Vessels and Piping, 79(12):807 - 818, 2002. ISSN 0308-0161. URL https://doi.org/10.1016/S0308-0161(02)00103-5.

[10] Miikka Väntänen, Joona Vaara, Jukka Aho, Jukka Kemppainen, and Tero Frondelius. Bayesian sequential experimental design for fatigue tests. Rakenteiden Mekaniikka, 50(3): 201-205, 2017. URL https://doi.org/10.23998/rm.64924.

Antti-Jussi Vuotikka

Global Boiler Works Oy

Lumijoentie 8, 90400 Oulu

antti-jussi.vuotikka@gbw.fi

Mikael Nyberg, Heikki Karhinen, Tero Frondelius

Wärtsilä

Järvikatu 2-4, 65100 Vaasa

mikael.nyberg@wartsila.com, heikki.karhinen@wartsila.com

tero.frondelius@wartsila.com 